\title{
Entrevista com Embaixador Gonçalo Mourão, chefe da Divisão do México, América Central e Caribe, do Ministério das Relações Exteriores, sobre as relações do Brasil com os países do Caribe (22 de abril de 2008)
}

Qual a sua avaliação geral e introdutória das relações Brasil - países da bacia do Caribe?

Até muito pouco tempo, era um súbito espanto, para um brasileiro, o de se defrontar com este conceito de Bacia do Caribe. O Caribe, para nós, era uma região geográfica em que se inseriam as ilhas do mar caribe e onde, de maneira geral, se falava inglês. O resto era Cuba, a República Dominicana e a América Central. O chamado "caribe sulamericano" nunca foi pensado como Caribe : a Venezuela e a Colômbia eram países eminentemente sul-americanos e "as guianas" uma espécie de excrescência políticogeográfica. O Haiti era uma profunda curiosidade desconhecida. O México era o México e os Estados Unidos os Estados Unidos.

Isso hoje mudou mas não muito. Cuba, a República Dominicana e o Haiti são Caribe mas o México continua sendo o México, os Estados Unidos os Estados Unidos e a América Central a América Central. A Venezuela, a Colômbia e as Guianas são, cada vez mais, América do Sul.

Por isso, vinha sendo muito difícil, para um brasileiro, falar de alguma maneira fecunda sobre "os países da bacia do Caribe" e, ainda mais, sobre as relações do Brasil com tais países como um todo.

É verdade, entretanto, que nossas relações com os países da América Central e nossas relações com os países insulares do Caribe têm sua história. Uma história que se vem intensificando enormemente nos últimos cinco ou seis anos e que parece - e esperamos - nos levará a que, em muito breve tempo, possamos começar a falar com naturalidade das relações do Brasil com os países da bacia do Caribe.

O fato é que nossa percepção, ademais, ainda é a de que os assim chamados países da bacia do Caribe, eles próprios, não têm uma consciência muito límpida de pertencerem a algo que seja muito mais do que as margens de um mesmo mar. E, mesmo assim, tenho cá minhas dúvidas sobre se em Santa Lúcia acredita-se que o mar que a banha é o mesmo que banha a Nicarágua e vice-versa. Claro, há subjacentes alguns ritmos musicais comuns e alguma história igualmente perversa de exploração colonial, resquícios comuns de alguma maneira caraíba de cozinhar um peixe e o fato indiscutível de que cada um dos países ali tem consciência plena de que fabrica o melhor rum do mundo. Mas não creio que na Guatemala, por exemplo - para não dizer no Brasil - muita gente saiba que existe um rico arco de 13 países independentes costurando a entrada do mar das Caraíbas.

Essa realidade, porém, começa a se confrontar hoje com um aumento inquestionável do conhecimento mútuo, da procura mútua pelo vizinho do lado. Politicamente, a atuação conjunta na OEA (Organização dos Estados Americanos), a atividade em organismos internacionais desenvolvida pelos diversos GRULACs (Grupo latino-americano e caribenho) e os esforços da AEC (Associação dos Estados do Caribe - na qual, aliás, o Brasil tem o status de observador) vão contribuindo para alargar os passos na direção de uma convivência mais estreita. Por outro lado, os esforços de integração que cada uma das regiões deste nosso continente americano vem realizando - e penso na Caricom, no SICA, 
no Grupo Andino e no Mercosul - vão apontando para uma nova conceitualização da integração, ao começar a deixar patente que uma espécie de integração de integrações é mais do que urgente para os países da América Latina e do Caribe.

Deste tal ponto de vista, aquele conceito de países da bacia do Caribe pode vir a adquirir uma importância relevante. De fato, nesta bacia do Caribe convergem e, por vezes, se sobrepõem aqueles esforços regionais de integração ; e o Brasil, que acredita e se empenha, atualmente, na busca de uma integração latino-americana-caribenha, deve aprofundar aquele conceito.

Feita essa ressalva, por assim dizer, metodológica e voltando à pergunta inicial, pode-se dizer que a avaliação geral das relações do Brasil com as três margens da bacia do Caribe - a insular, a centro-americana e a sul-americana - tende para o positivo. Como a personalidade sul-americana dos países do Caribe sul-americano ainda se sobrepõe, para o Brasil, a qualquer outro traço que possam ter, limitarei minhas observações aqui ao Caribe insular e à América Central do Panamá ao Belize.

O que primeiro nos chama a atenção quando nos debruçamos sobre as relações atuais do Brasil com aqueles países é o desenvolvimento espetacular que vêm conhecendo nos últimos cinco ou seis anos. Logo em seguida, salta aos olhos que não apenas o Brasil saiu decidido em procura daqueles países mas que eles, também, têm iniciado uma busca pelo Brasil com afinco. Aquela decisão e afinco são ainda matizados, por certo, pela novidade e pelos desconhecimentos naturais que as novidades desvelam. O conhecimento desses desconhecimentos, por assim dizer, é, por outro lado, um dos principais fascínios que induz fortemente àquele desejo de intensificação do relacionamento.

Um exemplo cabal é o descobrimento do Haiti pelo Brasil e do Brasil pelo Haiti, em decorrência da participação brasileira na Minustah e dos esforços de cooperação bilateral que nasceram com aquela participação. Foi também a presença no Haiti que acarretou, para o Brasil, uma aproximação política com os países do Caribe anglófono que revelou, tanto ao Brasil quanto àqueles países, realidades e vocações de cooperação políticas antes insuspeitadas de parte a parte.

Finalmente, uma terceira impressão que nos marca é a de que tanto o Brasil quanto aqueles países desenvolveram uma consciência plena de que o caminho de uma integração, embora ainda não muito claro, é o único que pode levar à construção de um verdadeiro e duradouro desenvolvimento de nossos países que contemple um crescimento solidário não apenas no aspecto econômico-comercial mas, também, social, cultural e político. Nem todos, naturalmente, têm o mesmo grau de nitidez ao contemplar aquele caminho mas creio que há uma percepção geral de que é o caminho mais largo que se apresenta, embora possa ser, também, por vezes, longo.

O que poderia comentar sobre as relações comerciais vigentes entre o Brasil e aqueles países? Como será possível equilibrar a balança vigente entre as partes? A que razões atribuir o grande sucesso dos bens brasileiros comercializados no Caribe?

As relações comerciais entre o Brasil e os países do Caribe têm-se revelado como um dos aspectos mais dinâmicos daquele relacionamento nos últimos anos. Essa situação faz com que possamos acreditar que as relações comerciais continuarão a ser, sem dúvida, 
florescentes e crescentes no presente e no futuro imediato. Os números são contundentes e vou me permitir citar alguns : o comércio bilateral do Brasil com os países da CARICOM, por exemplo, passou, de cerca de US\$ 660 milhões em 2002, a cerca de US\$ 1,4 bilhão em 2004 e a cerca de US\$ 2,6 bilhões em 2007. Ou seja, duplicou em três anos e, em cinco anos, cresceu em mais de $400 \%$. É verdade que esse comércio abriga um desequilíbrio flagrante e altamente indesejado, onde as exportações brasileiras respondiam, em 2002, por cerca de $90 \%$ do total e, em 2007, continuavam a representar os mesmos $90 \%$. Um dado positivo, entretanto, é o de que se é verdade que o desequilíbrio em favor do Brasil continuou gritante, é também verdade que as exportações daqueles países para o Brasil cresceram ao mesmo nível naquele período, ou seja, o dinamismo comercial bilateral foi concomitante dos dois lados, tendo as importações brasileiras provenientes da CARICOM passado de cerca de US\$ 38 milhões em 2002 para cerca de US\$ 175 milhões em 2007, ou seja, um crescimento de 500 por cento em cinco anos.

Se considerarmos os números relativos ao comércio Brasil x SICA, a situação é semelhante : em 2002 o comércio bilateral montava a um total de cerca de US\$ 600 milhões e em 2007 representava US\$ 1.680 milhões, ou seja, um crescimento de cerca de 300 por cento ; do mesmo modo, as exportações brasileiras passaram de US\$ 550 milhões em 2002 para US\$ 1.490 milhões em 2007, enquanto as importações passavam de US\$ 47 milhões em 2002 a cerca de US\$ 200 milhões em 2007. Ou seja, também aqui o crescimento das exportações do SICA para o Brasil cresceram percentualmente mais que as importações de produtos brasileiros pelo SICA.

Uma constatação otimista se impõe, a partir desses números: se consideramos que aquele crescimento invejável se deu sem que qualquer instrumento de facilitação de comércio tenha sido adotado entre o Brasil e aqueles países, só podemos esperar que um esforço institucional, de parte a parte, por intensificar o comércio bilateral levará a índices ainda maiores o crescimento do intercâmbio.

O Brasil acredita que aquele esforço deve ser buscado, não apenas a nível bilateral, mas a nível dos mecanismos de integração existentes. Ou seja, devemos procurar uma intensificação urgente dos contactos e negociações entre o Mercosul, a Caricom e o SICA, com vistas à institucionalização de acordos de facilitação daquele comércio.

Permanece, naturalmente, o problema do desequilíbrio da balança comercial - ou das balanças comerciais. Seria um ponto-de-vista pessimista dizer simplesmente que este problema não terá solução a curto ou médio prazo no que diz respeito à maioria dos países do Caribe. Não terá, é verdade, mas de maneira direta. De uma maneira indireta, porém, podemos dizer que as relações comerciais do Brasil com aqueles países têm uma vocação tendente ao equilíbrio a medida que se vão desenvolvendo. Essa noção está intimamente ligada à parte da pergunta sobre o por que do sucesso dos bens brasileiros na região. Para exemplificar de maneira simplista meu pensamento, creio que seria algo assim : se compro um prego por dois dólares nos Estados Unidos ou na Itália, isto, naturalmente, significará um desequilíbrio em minha balança comercial com aqueles países que não me compram mais do que uma manga por cinqüenta centavos, ou seja, terei um desequilíbrio desfavorável de um dólar e meio. Se eu comprar, porém, um prego no Brasil por um dólar, mesmo que o Brasil não me compre nada meu desequilíbrio será desfavorável em apenas um dólar.

Essa é uma maneira de buscar com que o aumento do comércio com o Brasil signifique um aumento no equilíbrio da balança comercial ; não necessariamente da balança comercial com o Brasil mas da balança comercial do país. 
Outras maneiras são, seja um esforço por um aumento dos investimentos produtivos brasileiros naqueles países, seja um esforço pelo aumento puro e simples das importações brasileiras. Ambas situações necessitarão da implementação de uma política comum de divulgação e conhecimento de oportunidades que, acredito, no caso dos países do Caribe com o Brasil, dificilmente seria possível a nível estritamente bilateral mas requererá uma atuação de amplitude regional.

Como avalia a cooperação técnica horizontal vigente entre o Brasil e os países do Caribe? A gradual expansão do etanol nos países do Caribe aparentemente é um tópico relevante na agenda vigente : o que poderia comentar sobre o assunto?

A cooperação técnica bilateral é bastante dinâmica mas temos a intenção de dinamizá-la sempre e mais, não somente porque o Brasil dispõe de possibilidades de fornecimento de cooperação crescentes mas, também, porque temos sido procurados para tanto pela maioria dos países da região.

Apenas para dar uma idéia do que se faz e do que pode ser feito, considere-se que em 2007 a Agência Brasileira de Cooperação, que é a agência do governo brasileiro prestadora de cooperação técnica, realizava cerca de $27 \%$ de suas ações em 11 países da região do Caribe e América Central, o que representava, em termos quantitativos, cerca de quatro milhões de dólares norte-americanos - 20\% do montante total da cooperação - , para um total de cerca de 80 atividades.

Esses projetos se desenvolvem nas áreas mais variadas, de saúde a educação, de transportes a meio ambiente, de energia a agropecuária, de defesa civil a área jurídica e administrativa e tanto são realizados no Brasil, sob forma de treinamento e capacitação de pessoal, como nos próprios países beneficiários.

A intenção de dinamizar a cooperação, a que me referi acima, prende-se sobretudo à promoção de novos acordos de cooperação com os poucos países com os quais não temos ainda tal instrumento, que é o principal fio condutor dos projetos de cooperação. Nos últimos três anos, foram enviadas missões a vários países do Caribe insular para propor projetos de acordos de cooperação e alguns foram já assinados, encontrando-se outros em vias de negociação.

A contribuição que o Brasil tem dado e se propõe a dar é sobretudo na área do compartilhamento de experiências adquiridas e de tecnologias desenvolvidas que se adaptam a situações semelhantes de desenvolvimento e de inserção social. Mas, também, na área de tecnologias mais refinadas como é o caso da produção de biocombustíveis, cooperação esta que tem, ademais de uma alta potencialidade de rentabilidade econômica, aspectos relevantes de promoção social.

A respeito deste item, especificamente, cumpre ressaltar que o Brasil não pretende que cada país da região se transforme em um grande produtor de biocombustíveis de todo tipo. O que acreditamos, simplesmente, é que pudemos desenvolver no Brasil, nos últimos anos, uma tecnologia e uma política de utilização desses novos combustíveis que significou, para nós, um importante fator de desenvolvimento econômico e, em certos aspectos, também social. Acreditamos que a utilização dos biocombustíveis, independente do fato de que determinado país os produza ou não ; significa para todos uma redução 
considerável na conta do petróleo e que é mais significativa ainda nos países da região do Caribe insular e da América Central que, com pouquíssimas exceções, devem importar a quase totalidade, se não a totalidade, do óleo que consomem.

O biocombustível é mais barato que a gasolina e sua utilização crescente representa economias significativas para o mercado como um todo. Assim, alguns países terão condições de desenvolver uma indústria de produção de etanol, outros terão melhores condições de desenvolver uma indústria de biodíseis e estas teconologias, de que o Brasil dispõe, o Brasil se oferece para compartilhá-las.

Certas empresas brasileiras do ramo da construção civil estão interessadas em participar dos mais importantes empreendimentos de infra-estrutura vigentes nos países da bacia do Caribe. Como o Governo brasileiro aborda esta temática?

O Brasil conta, hoje, com uma quantidade de empresas do ramo da construção civil que são empresas de excelência no setor, a nível internacional. A experiência que desenvolveram no Brasil nas últimas décadas, levou-as a procurar operar em outros países com bastante sucesso e algumas delas já operam tanto ou mais no exterior que dentro do Brasil.

O Governo brasileiro vê esta expansão, naturalmente, sob a ótica de uma maior participação de empresas brasileiras no mercado internacional, mas, também, sob a ótica da contribuição que o Brasil pode dar ao desenvolvimento infra-estrutural de outros países em desenvolvimento. A participação daquelas empresas em obras em outros países é incentivada, assim, também como a materialização de um aspecto de que se pode revestir o que consideramos como cooperação sul-sul. Desse modo, a formação e capacitação de pessoal técnico local para ser empregado nas obras contratadas é uma constante.

Como avalia a participação do Banco Nacional de Desenvolvimento Econômico e Social (BNDES) no processo de financiamento de projetos de interesse comum brasileirocaribenhos?

O Brasil é um país em desenvolvimento que propugna pela cooperação entre os países em desenvolvimento, a chamada cooperação sul-sul. Nesse sentido, o Governo brasileiro entende que o Brasil, podendo dispor de uma parcela de sua riqueza para incentivar e promover aquele aspecto da cooperação internacional, deve fazê-lo. E grande parte da parcela de que dispõe é a que é gerida pelo BNDES.

Existe alguma possibilidade de expandir as atividades e a presença da Petrobras na bacia do Caribe, particularmente em questões ligadas à exploração de petróleo e gás natural em águas profundas? 
A Petrobrás é hoje uma das grandes empresas petrolíferas do mundo e vai-se fazendo presente em várias regiões. Na América Central e no Caribe ela já está presente e vem mantendo entendimentos com governos ou empresas de vários países ali. Como uma empresa de excelência em vários aspectos de suas atividades e que tem, ademais, assumido responsabilidades sociais no Brasil, a Petrobrás é uma parceira natural para compartilhar com os países da região os esforços pelo desenvolvimento energético, esforços que, ademais, não se restringem, no caso da Petrobras, apenas à exploração de petróleo mas também abarcam a produção de biocombustíveis.

Qual a avaliação brasileira sobre a situação dos diferentes processos de integração vigentes no continente americano e particularmente sobre as conseqüências destes processos de integração para as relações brasileiro-caribenhas?

A América Latina e o Caribe vivem um momento de intensa atividade integracionista. Os diversos processos de integração regionais vão se desenvolvendo a ritmos e densidades diferentes mas com um traço comum : a determinação dos países envolvidos em levá-los adiante. O Brasil é um dos países que tem aquela determinação.

A Constituição brasileira estabelece, no parágrafo único de seu artigo $4^{\circ}$, que a integração econômica, política, social e cultural dos povos da América Latina é uma das metas do Estado Brasileiro (e por América Latina entenda-se, também, o Caribe). Isso vem sendo praticado por todos os governos do país desde a promulgação da Constituição de 1988 e mesmo, para não faltar à justiça, desde antes.

Começamos nossos esforços com a criação e institucionalização do Mercosul, pugnamos hoje pela institucionalização da UNASUL e pretendemos, em breve, partir para um exercício maior e mais ambicioso de integração. Isso, porque acreditamos que a integração latino-americana-caribenha é o melhor cenário para a obtenção de um desenvolvimento regional geral, consistente, solidário, compartilhado e socialmente significativo.

Acreditamos que seja surpreendente podermos nos entender sub-regionalmente, digamos, a Caricom ou o Mercosul, por exemplo, com a União Européia e não nos sentarmos nós mesmos nem para conversar entre nós. Os diferentes processos de integração estão bastante maduros para que possamos começar a pensar seriamente em uma espécie de integração de integrações em nossa região latino-americana-caribenha.

Esses diferentes processos tem-nos mostrado que a integração regional é o melhor caminho para o desenvolvimento sustentado e esta experiência deve ser utilizada para a consecução de uma intensificação desses processos de integração, rumo à verdadeira integração de toda nossa região. 
Como avalia a situação atual e as perspectivas futuras do diálogo político-diplomático entre o Brasil e os países da bacia do Caribe, em geral? Quais são os principais tópicos da agenda político-diplomática vigente?

O diálogo político-diplomático entre o Brasil e os países da América Central e Caribe nunca esteve tão florescente. O que não quer dizer que não deva ser intensificado, pelo contrário, a tendência que se revela hoje deve ser o impulso para uma maior aceleração daquele processo variado de diálogo fecundo.

Alguns pequenos exemplos demonstram com contundência a intensidade do momento presente : nos últimos cinco anos, o Brasil recebeu 11 visitas de Presidentes ou Primeiros-Ministros de países da região ; o Presidente Lula da Silva esteve em visita oficial em 9 países ; nos últimos cinco anos assinamos com os países da região mais acordos do que em todos os anos anteriores de nosso relacionamento ; o Brasil abriu mais representações diplomáticas na região e hoje só não dispõe de Embaixadas residentes em apenas cinco países do continente.

Do mesmo modo, não é só o relacionamento bilateral do Brasil com os países centro-americanos e caribenhos que se tem intensificado mas, também, o diálogo do Brasil com os sistemas de integração regional ali existentes. Assim, até o final deste semestre, o Presidente Lula da Silva terá participado de sua segunda cúpula com os demais Presidentes do SICA, depois da que se realizou na Guatemala em 2005. Há cerca de um ano, o Brasil acreditou seu embaixador em Georgetown como Representante Permanente junto ao Secretariado da Caricom, que tem sede naquela cidade ; e em poucos meses, com a instalação da Embaixada residente em Castries, Santa Lucia, o Embaixador do Brasil naquela capital deverá ser acreditado, também, na qualidade de observador permanente junto ao Secretariado da Organização dos Estados do Caribe Oriental, que ali tem sua sede. Há alguns anos o Brasil vem participando, como observador, das reuniões da Associação dos Estados do Caribe e tanto o Presidente Lula da Silva foi levado a participar de reunião da Cúpula da Caricom quanto o Chanceler Celso Amorim foi chamado a participar de reuniões de Chanceleres daquela Comunidade.

Toda esta variada atividade de encontros políticos de alto nível e diplomáticos têm propiciado uma diversificação das relações do Brasil com aqueles países que se reflete no próprio aumento daqueles encontros. É uma espiral virtuosa que se nutre de si mesma e cresce a medida que prospera.

Nem podia ser de outra maneira, em um mundo onde os problemas vividos pelos países em desenvolvimento se revelam cada vez mais semelhantes, as soluções buscadas também cada vez mais semelhantes e se vai fazendo inquestionável a certeza de que é entre nós que encontraremos a mais transparente e invariável solidariedade na cooperação para o desenvolvimento.

As mudanças climáticas, os riscos ambientais, os protecionismos comerciais de toda espécie são apenas alguns dos aspectos da realidade internacional que nos empurram, ao Brasil e aos países centro-americanos e caribenhos, para uma mesma margem do grande rio por onde vai passando o desenvolvimento econômico e social. A conscientização comum desta realidade pauta nossa agenda político-diplomática comum. 
Incide o fato de ter governos de orientação democrática na maioria dos países caribenhos no momento de formular e implementar a politica brasileira naquela região? Como e por que?

Incide e não incide, pois, para o Governo brasileiro, todos os países da região têm, cada qual a sua maneira, um regime democrático. A política brasileira para a região não pretende prender-se a qualquer contingência dos tempos que correm mas almeja construir um relacionamento proveitoso para todos os povos da região.

O que poderia comentar sobre a situação atual no Haiti? Quais os principais ensinamentos e resultados da Minustah? O que poderia dizer para os que, no Brasil e no exterior, têm-se pronunciado de forma contrária à presença de militares brasileiros naquele país?

Esta pergunta, por si só, já daria vazão a todo um ensaio de algumas dezenas de páginas. Buscando alguma concisão, creio que podemos dizer, antes de tudo, que a situação atual no Haiti ainda não é a situação de estabilidade que o povo daquele país deseja. Não falo de estabilidade como reflexo de segurança mas de estabilidade como resultado da existência de condições mínimas de dignidade existencial. O Haiti não é hoje mais ou menos violento, no que diz respeito à segurança individual das pessoas, do que uma grande quantidade de países pelo mundo a fora. Mas é ainda um dos países mais violentos no que diz respeito à falta de condições básicas para uma vida digna da maioria de seus habitantes.

Para ajudar os haitianos a enfrentar essa situação foi que o Brasil aceitou participar militarmente da Minustah mas não apenas militarmente. Desde o começo insistimos que a necessidade de uma presença internacional não se prendia exclusivamente ao envio de tropas que pacificassem os ânimos mas, também e sobretudo, à montagem de um sistema de ajuda internacional que contribuísse decididamente para $\mathrm{o}$ fortalecimento das instituições e a retomada do crescimento econômico e da restauração da justiça social. Aos poucos, a comunidade internacional se convenceu da validade daquela avaliação e creio que podemos dizer que este talvez possa ser um dos maiores ensinamentos da Minustah : não é apenas a força armada quem resolve os problemas da instabilidade que a pobreza causa.

Quanto a resultados, talvez um dos mais importantes a assinalar aqui, já que estamos tratando de relações regionais, seja o de que um esforço solidário regional e consciente é capaz de trazer um auxílio por vezes mais eficaz que uma intervenção multinacional descosturada. Por outro lado, a possibilidade que se apresentou, diante do problema haitiano, para os países latino-americanos e caribenhos de atuarem com aquele espírito de solidariedade, fortaleceu, sem dúvida, a conscientização de pertencermos todos, de algum modo, a um mesmo espaço humano e de sermos todos, de algum modo, igualmente responsáveis por nos ampararmos mutuamente dentro desse espaço.

Como a pergunta indica, nem sempre a decisão de enviar tropas é bem compreendida, dentro e fora do Brasil. Em alguns dos outros países latino-americanos que 
voluntariaram tropas, o problema é ainda mais premente que no Brasil e as discussões políticas sobre a continuidade daquela presença são bem mais delicadas. Prefiro acreditar que os que se pronunciam contrários àquela presença sejam movidos por uma generosidade que não teve ocasião de apreciar o esforço que está sendo feito em toda sua dimensão, que extrapola em muito a simples presença militar a qual, ademais, não é uma presença nacional mas que se dá sob a égide das Nações Unidas e segundo o desejo expresso e constante dos governos legalmente constituídos no Haiti.

Como avalia a reabilitação do diálogo político-diplomático entre o Brasil e o México após um periodo de certas divergências e dificuldades?

A retomada ampla do diálogo político-diplomático entre o Brasil e o México é uma das boas coisas naturais que acontecem hoje na América Latina e Caribe. São as duas maiores economias da região, os países maiores e mais populosos, talvez os mais adiantados científica e tecnologicamente, certamente dos mais presentes no cenário internacional e dos que mais se relacionam com o resto da totalidade dos países da região. Nada mais natural do que estarmos cada vez mais juntos e cada vez mais procurando dizermos as mesmas coisas em benefício do maior desenvolvimento da América Latina e do Caribe.

O Brasil e o México, por todas aquelas suas dimensões ímpares no continente, têm, por isto mesmo, uma outra dimensão que lhes é peculiar e que é a de conduzirem políticas voltadas para o benefício do desenvolvimento de nossa região. A responsabilidade do Brasil e do México no impulso a ser dado à integração de nossos países não pode ser obviada, até mesmo em nome daquela integração.

Se o México esteve por algum tempo distanciado da corrente maior do pensamento e da prática de integração da maioria dos países da América Latina e Caribe, a retomada de seu diálogo político-diplomático com o Brasil só poderá favorecer uma reaproximação. O México é, de certo modo, refém da realidade geográfica de sua fronteira com os Estados Unidos e isto todos nós, da Guatemala para baixo, entendemos muito bem ; o que era difícil de entender era o esquecimento que parecia envolver o México, em certo momento, de que ele também é refém de suas fronteiras ao sul, que são, ademais de meramente geográficas, também históricas e culturais.

O Brasil tem muito que aprender com o México e o México com o Brasil. Acredito que a intensificação do nosso diálogo bilateral em todas as áreas será estimulante e edificante para as relações entre os dois países e para as relações dos dois países com os demais da região.

O Presidente Lula da Silva recentemente visitou Cuba. O que poderia comentar sobre a posição brasileira diante do presente e do futuro do processo político cubano? 
O Presidente Lula, há pouco tempo, diante de certas críticas ao desenvolvimento do programa de biocombustíveis no Brasil, invectivou contra comentários ligeiros de algumas autoridades de outros governos ou de organismos internacionais, lembrando que o Brasil não se permite elucubrar sobre o destino que os países se dão a si mesmos. O Brasil tem ótimas relações com Cuba, em todos os níveis e continuará a desenvolvê-las como vem desenvolvendo com os demais países da América Latina e Caribe.

Em 2007, a direção Nacional do Partido dos Trabalhadores emitiu declaração apoiando uma eventual independência de Porto Rico. Existe alguma opinião brasileira com relação à continuidade do processo de descolonização naquela região do continente americano ?

O povo de Porto Rico deve escolher seu destino e o vem fazendo. Quando for sua decisão optar pela independência do país, não somente o Partido dos Trabalhadores mas todo o Brasil apoiará e reconhecerá aquela independência.

O Brasil é observador da Associação dos Estados do Caribe - AEC, foro regional que reúne 25 Estados ribeirinhos. Qual sua avaliação sobre a participação brasileira nesse foro?

A participação brasileira, como bem se ressalta, é de observador. Mesmo porque, o Brasil não pretende ser um país caribenho e não poderia ser, portanto, membro pleno. Como foro regional, e foro sobretudo de diálogo político, o Brasil estima que a AEC tem o importante papel de congregar todo o universo dos países da bacia do Caribe em torno da busca de soluções comuns para problemas comuns. Desde tal ponto de vista, a participação do Brasil se volta, especialmente, para a identificação daqueles problemas e daquelas soluções uma vez que, devido à própria natureza da formação social, cultural, econômica e política do Brasil, temos às vezes problemas e soluções bastante semelhantes, que se poderiam prestar ao estabelecimento de uma cooperação útil para ambas as partes.

Do mesmo modo, devo acrescentar, temos procurado participar, ultimamente, também como observador interessado, das reuniões da Organização dos Estados do Caribe Oriental - OECO, ali onde tal participação, com aquele mesmo espírito, é cabível. Nesse caso específico, esperamos, como disse, que com a abertura, muito proximamente, de nossa Embaixada residente em Castries, nossa interlocução e, portanto, nossas relações com a OECO se intensificarão para benefício de ambas as partes.

Certos atores não-estatais brasileiros e caribenhos têm freqüentes contactos e acordos. É o caso de empresários, de sindicalistas, de profissionais, de acadêmicos, de religiosos e até de grupos dedicados a atividades ilícitas. Qual sua avaliação sobre as atividades destes atores não-estatais e suas implicações na política caribenha do Brasil? 
A avaliação só pode ser a melhor possível. Todo o esforço, digamos assim, governamental no desenvolvimento de nossas relações com o Caribe - e não somente com o Caribe - pretende levar a que todos aqueles atores não-estatais desenvolvam mais e mais os freqüentes contactos a que se refere aqui - com exceção, naturalmente, dos que se dedicam a atividades ilícitas.

Assim como, internamente, os governos tratam de facilitar ao máximo o desenvolvimento de toda espécie de relações sociais saudáveis, também ao nível do relacionamento internacional o que se busca é que as sociedades civis dos países estabeleçam o maior grau de interação e integração possível. Nosso esforço por abrir Embaixadas em todos os países da região, por exemplo, não obedece a um mero desejo de ampliar a presença do Estado brasileiro naqueles países mas de criar as condições mais amplas possíveis para o estreitamento das relações entre nossos povos.

Têm alguma incidência os assim chamados "novos temas" das relações internacionais isto é, gênero, meio ambiente, questões sociais, temas culturais, migrações, transformações globais, dentre outros - na formulação da política brasileira para o Caribe? Caso a resposta seja positiva, vale consultar o como e o por que?

Se as nossas relações com o Caribe são, de certa maneira, novas, é certamente natural que estes "novos temas" tenham relevância. Mesmo porque, são temas que se apresentam, em sua complexidade e incidência, de maneira bastante semelhante no Brasil e no Caribe.

Para retomar a enumeração da pergunta, a valorização do gênero, a proteção ao meio-ambiente, a busca da justiça nas questões sociais, a relevância nacional dos temas culturais, a responsabilidade compartilhada da questão das migrações, as diversas fragilidades e oportunidades diante das transformações globais são aspectos da modernidade que requerem do Brasil e do Caribe respostas semelhantes. Em nossa política para região, portanto, assim como na política da região para com o Brasil, aqueles temas figuram em uma primeira linha do diálogo político. Um simples exemplo é o apoio firme dado pelo Brasil à proposta caribenha nas Nações Unidas de desnuclearização do Mar Caribe.

Incide nas relações brasileiro-caribenhas a atuação de atores extra-regionais e extracontinentais? Como e por que?

Incide, a medida que o palco do mundo hoje tem uma quantidade bem maior de protagonistas que há algumas décadas atrás. Até porque, um dos aspectos importantes das relações do Brasil com os países do Caribe é a busca de posicionamentos comuns diante de desafios globais que nos são apresentados. O exemplo que citei da desnuclearização do 
Mar Caribe é um deles. Os problemas da regulamentação do comércio internacional são outros. Assim, as relações internacionais hoje raramente se limitam aos aspectos bilaterais de sua problemática mas, via de regra, representam, sobretudo, a busca comum de posicionamentos comuns diante de situações que extrapolam aquele simples relacionamento.

Por vezes, a presença de atores extra-regionais é benéfica, como é o caso do esforço que conjuntamente realizam o Brasil, a Índia e a África do Sul para levarem juntos a outras regiões que não as suas, através do recém-criado Fundo IBAS, ações de cooperação para o desenvolvimento em países mais necessitados. Por vezes aquela presença é delicada, como é o caso do embate entre a China e Taiwan na área do Caribe. O fato é que a existência de uma consciência regional faz, invariavelmente, com que a presença de atores extra-regionais sirva, antes de tudo, para fortalecer aquela consciência e fortalecer, portanto, as ações em direção a sua maior solidificação.

O que gostaria de comentar que não foi abordado até agora nesta entrevista? O que poderia ponderar como considerações finais e mensagem de encerramento?

Gostaria, em primeiro lugar, de agradecer profundamente ao Professor Carlos Domínguez Avila e, por seu intermédio, à direção da revista Memórias, da Universidade do Norte, da Colômbia, por esta ocasião que me dá de expor com franqueza algumas opiniões a respeito das relações atuais e futuras do Brasil com os países da Bacia do Caribe ; ou, pelo menos, conforme assinalei logo ao início desta entrevista, com a maioria daqueles países.

O interesse, em primeiro lugar acadêmico, de uma instituição tão altamente conceituada como a Universidade do Norte, pelo que possa o Brasil achar de seu relacionamento com o Caribe é uma demonstração de que a academia está atenta às realidades da política internacional em nosso continente e isto é altamente louvável. O pensamento contribui para a orientação da ação e, às vezes, até mesmo para seu começo, de modo que é com grande interesse, também, que aguardo a edição deste número de Memórias, para conhecer melhor o pensamento de quem se ocupa e se preocupa com o desenvolvimento da região do Caribe.

Como disse acima, o Brasil não é um país caribenho. Assim como não é, tampouco, um país africano, nem um país europeu ou asiático ou do Oriente Médio. O Brasil é um país americano, mais especificamente latino-americano.

Ocorre, entretanto, que conformaram nossa cultura e identidade outras presenças além da latina e indígena e, assim, o Brasil tem uma importante componente africana, européia não latina, japonesa e árabo-judaica. Apenas para melhor contextualizar, podemos lembrar, como curiosidade, que o Brasil abriga, hoje, a maior colônia de libaneses e japoneses fora de seus países, por exemplo. Fomos formados, conformados e por vezes deformados por estes aluviões de gente diversa que seguiram os desbravamentos portugueses. Hoje, toda esta gente é o Brasil, do lado de cá das Américas.

Não somos caribenhos assim como não somos um país da Bacia do Pacífico mas uma consciência de pertencer a um mesmo destino histórico nos faz a todos, caribenhos, sul-atlânticos ou pacíficos, olharmo-nos como se vêem primos próximos. É esta espécie de 
familiaridade ontológica que nos congrega sempre que pensamos em nós mesmos. E o nosso tempo, cada vez mais, é tempo de pensarmos juntos em nós mesmos.

Assim é como vemos a maior aproximação que vamos vivendo entre os povos latino-americanos e caribenhos. O Brasil não é caribenho assim como o Caribe não é luso mas nascemos, ambos, de uma mesma aventura humana, somos ambos parceiros de um mesmo destino. E esse destino é o da intensificação da convivência, é o da recuperação dos bens comuns, é o da marcha solidária para um futuro de maior desenvolvimento e justiça social.

Pensarmos juntos aquele destino é o desafio que a revista Memória nos lança e espero que esta troca de idéias seja uma semente a mais neste jardim que vamos plantando e cultivando juntos.

Embaixador Gonçalo Mello Mourão

Diretor do Departamento da América Central e Caribe

do Ministério das Relações Exteriores do Brasil 